\title{
The Effectiveness of Educational Scaffolding Strategies in Developing Basic Scientific Operations of Kindergarten Children in Jordan
}

\author{
Ward Musbah Eldien Barqawi ${ }^{1} \quad$ Prof. Zahria Ibrahim Abdul-Haq ${ }^{2}$ \\ 1.Islamic Education College, Jordan \\ 2.Department of psychology, Jordan
}

\begin{abstract}
This study aimed to characterize the effectiveness of educational scaffolding strategies in developing basic scientific operations of kindergarten children in Jordan, the study sample consists of (45) children of kg2 level (5-6) years, was chosen intentionally, distributed to the two study groups: (22) children in the experimental group, and (23) children in the control group. They were chosen from the Islamic Educational College IEC Kindergarten affiliated with the Ministry of Education in Amman, for the academic year 2019/2020.To achieve the study goals, the researchers prepared the study tools represented in: list of basic scientific operations for kindergarten children, educational guide using educational scaffolding strategies, and basic scientific operations test for kindergarten children after making sure of its validity and reliability. The results of the study showed a difference in the adjusted mean scores of the educational scaffolding strategies group and the control group in favor of the educational scaffolding strategies group, ANCOVA was used to analyze children scores based on the variable of the teaching method, there is a significant difference at $(\alpha=0.05)$ between the adjusted mean scores of the overall performance on the Post-Test in favor of the experimental group, taught with educational scaffolding strategies compared with the control group who have been taught with traditional method. The adjusted mean of the experimental group was found to be (27.03) in comparison with the mean score of the control group (12.39), who were taught in the traditional method.
\end{abstract}

Keywords: kindergarten Children, scaffolding Strategies, Basic Scientific Operations, Educational Scaffolding. DOI: $10.7176 / \mathrm{JEP} / 12-33-08$

Publication date: November $30^{\text {th }} 2021$

\section{Introduction}

Children are small living-things that may ruin the place up-side down; they are a piece of humanity full of power, emotions, thoughts, and kindness; the creative thinker that will change the future; a sponge that can absorb every tiny action or information we give. In fact, parents and teachers can saturate this sponge with the appropriate knowledge and information. Usually, children first idol is the mother, followed with the teacher as the second idol, mothers and teachers are the scaffolders of children prior knowledge; their responsibility is to obtain a generation full of honesty, creativity, love, generous, peace, and harmony. Therefore, they have to help them reach their inner-peace in order to empower their self-confidence. Rather, they have to scaffold good habits without bullying attitudes. Children of today are men of future; the bright world is coming up with appropriate educational scaffolding strategies.

Vygotsky's socio-cultural theory (1978), children expand and convert the information they adopt into a situation through interaction with peers and adults (Cobb, 1996). Cooperative interaction between kindergarten children and more experienced persons occurs in both kindergarten and parents, and this significantly affects children's thinking and learning (Harkness, \& Super, 2002). Tutoring from mom is a substantial case in which children import shared meanings in a specific culture (Rogoff, 1990; Vygotsky, 1978). When children enter kindergarten, the teacher gradually takes over the role of being the primary instructor from the mother by preparing the environment with stimulating, challenging activity choices to facilitate children's engagement (Bredekamp, 1987). Thus, both parents' and teachers' involvement facilitate children's learning by managing the learning environment, presenting materials, or designing tasks (Coltman, Petyaeva, \& Anghileri, 2002).

The use of educational scaffolding strategies has been shown to be an effective method for providing differentiated strategies in kindergarten classroom and teacher's ability to provide differentiated instructions. It may help in reaching the range of children's learning; teachers encounter in their early childhood classrooms. Children within today's early childhood classrooms demonstrate a wide range of skills and experience a multitude of other risk factors. This diversity among young children indicates the necessity to investigate ways in which their different learning needs can be supported (Pentimonti, 2011).

ZPD is defined as the difference between children's actual and potential abilities. Vygotsky theorized that in order to cultivate children's learning, adults must provide children with mediated assistance, or social guidance. A level beyond independent learning yet within their ZPD (Bruner, 1981; Vygotsky, 1978; \& Wertsch, 1984). 


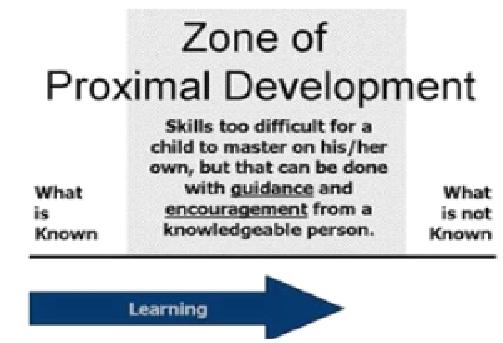

Vygotsky's idea of ZPD makes up the term scaffolding which describes the process of temporarily providing support to children within a social context. Gradually, with drawing this support, children become capable of independence in performing tasks. The process of educational scaffolding strategies has been supported through empirical research that explains a positive relationship between the use of educational scaffolding strategies in kindergarten classroom and children's academic outcomes (Berk, \& Winsler, 1995; Juel, 1996).

Piaget's theory of cognitive development explains the nature and development of human intelligence. The theory deals with the nature of knowledge itself and how humans gradually come to acquire, construct, and use it. It is mainly known as a developmental stage theory. Piaget was interested in the fact that children of different ages make different kinds of mistakes, while solving problems. He also believed that children are not like little adults who may know less. Children just think and say words in a different way, but as Piaget thinks that children have great cognitive abilities that let them depend on themselves (Franzoi, 2014).

What the current study tries to add is the demonstration of educational scaffolding strategies, and study the extent of its effectiveness on developing some of the basic scientific operations for kindergarten children (5-6) years, kg2, that enable them to scaffold in knowledge.

\section{Statement of the Problem}

Researchers found out that children lack the basic scientific operations which are: (observing, classifying, predicting, and measuring). Teachers also face problem using educational scaffolding strategies inside classroom. Having reviewed the relevant literature, the researchers figured out that the field of educational scaffolding strategies is poor in studies concerning implementing innovative techniques to develop basic scientific operations. Which are: observing, classifying, measuring and predicting. Hence, it was important to conduct this study as a step toward improving children's basic scientific operations and increasing their performance through implementing an educational scaffolding strategy which will help them switch from assisted learning to an independent one.

\section{Importance of the Study}

Theoretical \& Empirical Importance:

In the researcher's opinion, the findings of this study may contribute to:

- Develop children's ability and achievement. Children are our main concern and are the center of the educational process. All efforts should be geared towards improving and developing their performance especially in basic scientific operations. Many researches proved that Jordanian children encounter different problems in basic scientific operations; educational scaffolding strategies are effective ways for teaching basic scientific operations, as they influence the development of the children in that respect.

- To the knowledge of the researcher no researches have been conducted to investigate the effect of educational scaffolding strategies on developing kindergarten children 5-6 years of age in basic scientific operations in Jordan.

- Providing an experimental method to describe the effectiveness of educational scaffolding strategies on developing kindergarten children 5-6 years old on basic scientific operations.

- Kindergarten curriculum designers may benefit from this study by integrating educational scaffolding techniques into the curriculum and by providing them with relevant valuable.

- Teachers will have an additional and innovative educational scaffolding strategies that can be used to support children's comprehension through learning. It helps them as well to teach and

\section{Study Question}

The study seeks to answer the following main question: "What is the effectiveness of educational scaffolding strategies in developing basic scientific operations of kindergarten children in Jordan?"

The following sub-questions stem from the major one:

1. Are there statistically differences at the significant level $(\alpha \leq 0.05)$ between the mean scores of the experimental group (educational scaffolding strategies) in the post-test at the basic scientific operation scale 
(observing, classifying, predicting, and measuring) and those of their counterparts in the control group (traditional) of kindergarten children?

2. Are there statistically differences at the significant level $(\alpha \leq 0.05)$ between the mean scores of the experimental group (educational scaffolding strategies) in the post-test of kindergarten children due to the gender? 3. Are there statistically differences at the significant level $(\alpha \leq 0.05)$ between the mean scores of the experimental group (educational scaffolding strategies) in the post-test and consecutive-test?

4. Are there statistically differences at the significant level $(\alpha \leq 0.05)$ between the mean scores of the experimental group (educational scaffolding strategies) in the consecutive-test of kindergarten children due to the gender?

\section{Literature Review}

In their efforts to prove the effectiveness of educational scaffolding strategies on the development of basic scientific operations in kindergarten children (5-6) years at IEC kindergarten Amman, the researchers reviewed many books and studies about scaffolding strategy which has never been conducted in Amman before, to the knowledge of the researchers. Ejekwu, \& Inyon (2019) investigated the effect of scaffolding instructional strategies and gender on the performance of pupils in Basic Science and Technology in public primary schools in Rivers State in USA. Two particular objectives and two null hypotheses guided the study. Non-randomized pretest, post-test and control group experimental design were adopted by the study. The population consisted of four children; out of which 147 were taken as sample size using purposive sampling technique. The instrument for collecting data was the basic science and technology performance test. The data was analyzed using Analysis of (ANCOVA). The findings of the study revealed that there was a significant difference in Basic Science and Technology mean performance scores of pupils taught with scaffolding instructional strategies and those taught with conventional methods. Recommendations confirmed that scaffolding instructional strategy should be used in classroom teaching/learning interaction to enhance the teaching and learning of pupils as well as to improve their performance in all subjects.

Pentimonti, Justice, Yeomans-Maldonado, McGinty, Slocum, \& O’Connell (2017) examined teachers' use of dynamic processes when implementing static language lesson plans that explicitly required teachers to employ scaffolding strategies so as to differentiate instruction. Participants were 37 preschool teachers and 177 children in their classrooms. Videotaped classes were accomplished and coded for the frequency of teachers' use for six types of scaffolds. Children were assessed on measures of language skills. Findings indicated that teachers utilized scaffolding strategies at relatively low rates and that they applied low-support scaffolding strategies more frequently than high-support strategies. Furthermore, results suggested that the use of certain types of scaffolding strategies may be beneficial for children's development of language skills. The researcher recommended that teachers may benefit from professional development opportunities by focusing on the use of dynamic features of language interventions, such as scaffolding strategies, in preschool classrooms.

Al-Aila (2015) Investigated the effectiveness of using scaffolding strategy on developing seven graders reading comprehension skills. The study was conducted on a sample of (63) male and female students of the seventh grade in Gaza/Palestine. The sample was divided into two groups, the experimental group included (32) students taught reading comprehension by scaffolding techniques, while the control group included (31) students who were taught reading comprehension by the traditional way. The results of the study indicated that there were statistically significant differences between the mean scores of the experimental group and those of the control one, in favor of the experimental group. The differences were attributed to the use of scaffolding strategy. Based on the findings, the researcher recommended that English language teachers adopt scaffolding strategy in teaching English in general and reading in particular. He also recommended that coordinators, supervisors and specialists hold training courses to train English language teachers on using scaffolding strategy.

Hsin, \& Kai Wu (2011) conducted a study on young children's explanations of floating and sinking to investigate how scaffolding strategies provided by a tutor could promote their scientific understandings, (15) 4years old children and, (15) 5-years old children from a public kindergarten in northern Taiwan participated in that study. Pre and post- interviews were done on children to examine their understandings about how weight, volume, and material of an object relate to sinking and floating. In the first (2) groups, (16) teaching strategies based on six scaffolding principles were employed. Analyses of interviews revealed that before involvement, the group of 4 years old seemed to have a variety of explanations for sinking and floating and a majority of the 5 years old children used weight as an explanation for floatation. After intervention, both $4 \& 5$ years old in the scaffolding material and scaffolding groups improved their understanding of floating and sinking. Particularly, 3 children out of 5 children at the age of 5 years in the scaffolding-material group related the material of an object to its buoyancy and generalized their explanations to the objects made of the same material. Findings implied that manipulative experiences alone might not be sufficient for children to further their understanding about floatation, but combining teaching scaffolding with children's perceiving of the materials of objects was more effective. 
Sun (2011) investigated scaffolding preschool children's problem solving. A comparison between Chinese mothers and teachers across multiple tasks was made. The study was conducted on a sample of 57 children (29 girls - 28 boys) 5 years old, from 7 kindergartens in Beijing, mothers and teachers were also participants in the experiment, moms varied in educational levels. On the other hand, all teachers were professionally qualified, twenty-eight children worked with their mothers first, the problems were presented in the same order for both sets of dyads, problem solving episodes $(n=228)$ were videotaped and transcribed, an interaction turn was the unit of analyses, results indicated that teachers gave higher-level cognitive support and emotional feedback than what the mothers did. Mothers with high education provided higher optimal scaffolding than those with less education, but teachers' scaffolding for these two groups of children rarely differed; both mothers and teachers adjusted their scaffolding as an assignment of task characteristics, but teachers were more sensitive to task characteristics than mothers.

Pentimonti (2011) presented a study conducted by students of Ohio State University USA to examine the use and impact of scaffolding on the preschool classroom. The study was conducted to answer questions regarding the amount and types of scaffolding early childhood teachers use in their classrooms in addition to changes that may occur in their use of such strategies throughout the school year. Additionally, this study examined the scaffolding strategies employed by 37 early childhood teachers and the vocabulary skills of 173 children in their classrooms. Descriptive analyses provided information regarding amount and types of scaffolding that occurred in these classrooms, while growth curve analyses were conducted to characterize changes in teachers use of scaffolding types throughout the school year. Additionally, results demonstrate that teacher's use of low-support strategies increases over the school year and is influenced by children's initial vocabulary skill level, suggesting that teachers may be adjusting their use of this type of strategy to meet children's needs. Finally, study findings are promising, in that they suggest that the use of certain types of scaffolding strategies may be beneficial for children's development of vocabulary skills.

Pentimonti, \& Justice (2010) examined teachers' Use of Scaffolding Strategies in aloud reading in the Preschool Classroom in Ohio, USA. characterizing preschool teachers' use of six types of scaffolds (generalizing, reasoning, predicting, co-participating, reducing choices, eliciting) in the group of read aloud session. Results indicated that teachers showed a preference for three types of scaffolds, all of which were of low support, and that the three types of high support scaffolds occurred at very low rates. In addition to that, the results presented a substantial discrepancy between teachers' perceived frequency of use of specific types of scaffolds relative to their actual use. In fact, the findings propose that preschool teachers may assist in professional development by using a range of scaffolds, to include high support scaffolds beneficial to children who may need high levels of support.

Maranan (2017) focused on the correlation of mastery in basic process skills and attitude toward Science to grade 7 students' performance in San Pablo City. From the 200 respondents $74 \%$ or most of the students were of normal age of Grade 7 students 11-12 years old. (101) respondents or 50.5\% of the total were males while (99) respondents or $49.5 \%$ of the total respondents were females. In fact, students have homogeneity of "high positive attitude" towards all the items in the survey of attitude regarding Science except for classroom environment. Many students had outstanding performance in science, but many were fairly satisfactory and did not meet expectations that need immediate attention. In the light of the aforementioned findings, the following conclusions are drawn: The null hypothesis states that the mean level of students' mastery of the basic process skills which is not significantly related to performance in Science is partially supported. As indicated in the findings, the null hypothesis statement that there is no significant relationship between students' attitude and performance in Science is partially confirmed.

El-Keey (2017) examined the development of science process skills and some of accompanying skills through observing life cycle of silkworm by kindergarten child. Two research questions and thirty-two hypotheses guided the research. The hypotheses were tested at $\mathrm{p} \leq 0.01$ level of significance. The pretest and posttest experimental and control group design were used in the search. A sample consisting of (34) preschoolers was randomly selected from star baby kindergarten - Tanta district, Egypt. Teaching the experimental group was through science process skills and some accompanying skills, using the program based on observation of life cycle of silkworm, while the control group was taught through lecturing. 3 validated tools called scale of science process skills; two note cards for SPS and some of accompanying skills. Specifically, it was founded that observation life cycle of silkworm by kindergarten child was important for the acquisition and development of science process skills and some accompanying ones. There were differences with statistical significance at all levels of significance among individuals of both the experimental and control groups in some basic science skills (observation, classification, measurement, and prediction), in favor of the experimental group which was taught through the integrated experience approach in the deferred exam; while no difference was found with statistical significance at the level of $(\alpha \leq 0.05)$ attributed to gender variable in (observation, classification, measurement, and prediction) in the deferred exam.

Previous studies were examined and investigated scaffolding strategies in different ways, such as their 
impact, use, effectiveness, and efficacy on other variables. For example, reading aloud, language instructions, floating and sinking concept, problem-solving, acquisition of literacy, basic science \& technology, and reading comprehension. As we notice these variables were concerned with basic scientific operation skills: observing, predicting, reasoning, measuring, problem-solving, and classifying. They didn't offer any solution through educational scaffolding strategies, having the same goal. Which is to examine the impact and effectiveness of educational scaffolding strategies on basic scientific operation skills.

On the other hand, we noticed some recent studies talking about basic scientific processes and operations which were held to empower the know-how of using basic scientific operation skills in the current study and to consider how do basic scientific operations and processes take place in every teaching method. In addition, recent studies have the same results indicating that educational scaffolding strategies have a remarkable positive effect on children's and adult's basic scientific operation skills. The findings of these studies agreed on that educational and instructional scaffolding strategies enhance children's and adult's self-confidence, critical thinking, higher order skills, and achievements.

The findings and recommendations of the previous studies highlighted the importance of considering educational scaffolding strategies such as: show and tell, tap into prior knowledge, give time to talk, pre-teach vocabulary, use visual aid, and pause, ask questions, pause, review; in order to improve basic scientific operation skills. Especially, observing, measuring, classifying, and predicting. Thus, this study complies with such studies regarding the importance of educational scaffolding strategies.

How did the current study differ from the previous ones?

- As far as the researchers is concerned, the current study deals with scaffolding and basic scientific operation skills to be conducted in Amman.

- The researchers modified the strategies and techniques to fit Jordanian children in Amman.

- Recent studies investigated the basic scientific operations in different ways, the current study specifies the basic scientific operations sub-skills, as observing, classifying, predicting and measuring.

- This study identified the educational scaffolding strategies and the basic scientific operation skills which suited Jordanian children 5-6 years of age.

- The previous studies used different data collection techniques: pre-test, post-test, observation, children reflections, interviews, questionnaire, checklists, quizzes. The current study used two tools a test $\&$ a platform.

What makes the current study unique is gathering two important variables in one study: educational scaffolding strategies and basic scientific operations. These two variables are substantial for children to allow them enter primary level in school with more self-confidence, knowledge, and leading skills.

Method

\section{Population and Sample of the Study}

The population of the study comprises all second-level children (males and females) of kindergartens in Amman/Jordan (2019-2020), Two classes were taken as a sample which consisted of (45) males and females' children who were distributed into two groups; an experimental group of (22) children (9) girls and (13) boys, and control group of (23) children (9) girls and (14) boys. Flipping a coin was used to enroll those classes into experimental and control groups. These groups were randomly chosen from a purposive sample from Islamic Educational College Kindergarten (IEC) Amman/Jordan.

The two groups were chosen from the same school to be equivalent in the social, cultural, and demographic characteristics in terms of group and gender, as shown in Table (1):

Table (1) Demographic Characteristics of Respondents

\begin{tabular}{cccc}
\hline Variable & Category & Frequency & Percent \\
\hline \multirow{2}{*}{ Group } & Control & 22 & $48.9 \%$ \\
& Experimental & 23 & $51.1 \%$ \\
\multirow{2}{*}{ Gender } & Male & 28 & $62.2 \%$ \\
& Female & 17 & $37.8 \%$ \\
\hline \multirow{2}{*}{ Equivalen }
\end{tabular}

Equivalence of the Two Study Groups (Experimental and Control)

To ensure the equivalence of the two groups (experimental and control), arithmetic averages and standard deviations were calculated for the Pre-Test of basic scientific operation skills. T-Test was also used for differences between the mean scores of the study sample on the scale of basic scientific operation skills for kindergarten children (5-6) years of age, as shown in Table (2): 
Table (2) Independent Sample t-test of the Experimental and Control Groups in the Pre-Test

\begin{tabular}{cccccccc}
\hline Skills & Group & Number & Mean & Sd. & df & t & Sig. \\
\hline \multirow{2}{*}{ Observing } & Experimental & 22 & 2.23 & 1.60 & \multirow{2}{*}{43} & 0.660 & 0.513 \\
& Control & 23 & 1.91 & 1.59 & & & \\
Classifying & Experimental & 22 & 2.09 & 1.11 & 43 & 0.373 & 0.711 \\
& Control & 23 & 1.96 & 1.30 & & & \\
\multirow{3}{*}{ Predicting } & Experimental & 22 & 2.14 & 1.42 & 43 & 0.116 & 0.909 \\
& Control & 23 & 2.09 & 1.44 & & & \\
Measuring & Experimental & 22 & 1.73 & 1.28 & 43 & 0.308 & 0.760 \\
& Control & 23 & 1.61 & 1.31 & & & \\
Total & Experimental & 22 & 8.18 & 2.92 & 43 & 0.601 & 0.551 \\
& Control & 23 & 7.57 & 3.87 & & & \\
\hline
\end{tabular}

Table (2) reveals that students' scores for both groups were almost equivalent in Pre-Test before applying the experiment in the basic scientific operations scale (observing, classifying, predicting, and measuring skills). This indicated that the two groups were equivalent before starting the experiment.

This also showed that the difference between scores of both groups on the Pre-Test the basic scientific operations scale (observing, classifying, predicting, and measuring skills) test was not statistically significant.

\section{Instruments of the Study}

To achieve the goals of this study, the researchers-built tools which were subjected to the necessary procedures of reliability and validity and are presented as follows:

List of Basic Scientific Operation Skills

To prepare a list of basic scientific operations for $\mathrm{kg} 2$ children (5-6) years of age. A list of basic scientific operation skills for kindergarten children has been identified after the researchers made the following steps:

- $\quad$ Review the researches and studies that dealt with basic scientific operations.

- Review kindergarten children characteristics references.

In light of this the researchers prepared an initial list of basic scientific operation skills needed for kindergarten children as follow:

Observing Skills (6)

Classifying Skills (7)

Predicting Skills (8)

Measuring Skills (6)

The list was presented to a group of experts in education, psychology, measurement, and evaluation in Isra University, Balqa University, Petra University, Mutah University, and Zarqa University, consisting of (12) arbitrators they were asked to:

Indicate the suitability of sub-skills for each of the basic scientific operations.

Indicate the suitability of sub-skills for kindergarten children.

Modify what needs to be modified and add what they deem appropriate.

Accordingly, a list of basic scientific operations was finalized as:

Observing Skills (4)

Classifying Skills (3)

Predicting Skills (4)

Measuring Skills (3)

Basic Scientific Operations Test

After the researchers reviewed educational literature from specialized studies and books and educational researches related to basic scientific operation skills, including: the study of El-Keey (2017), and the study of Maran (2017). In addition to some books that took up lists of basic scientific operations, the researchers designed the basic scientific operations test that were consisted of (27) activities of basic scientific operation skills. It was referred by a panel of experts who reduced it to (14) activities. (14) activities distributed on (4) basic scientific operations: (observing, classifying, predicting, and measuring skills).

Test Validity

The test was presented in its preliminary form to a number of experts specialized in kindergarten, educational psychology, measurements, evaluation, and English language to verify the validity of the test in terms of appropriateness of its questions to basic scientific operations and their suitability for the age of kindergarten children, language structure and correctness, and some formal notes to determine the suitability of the test for its goals.

Test Reliability

To ensure consistency of test items, the researchers used the Test and Re-Test (Test/Re-Test) where the test was applied to an exploratory sample of (15) children from outside the sample studying in Topaz Academy 
Amman/Jordan, two weeks after the first application Re-Test was applied for the second time to individuals of the same sample, Pearson correlation coefficient was calculated for the first and second application on the basic scientific operation and test scores.

Table (3) Coefficient of Test Stability in Basic Scientific Operation Skills

\begin{tabular}{cc}
\hline Basic Scientific Operation Skills & Coefficient of Stability - Personal Correlation \\
\hline Observing & 0.87 \\
Classifying & 0.85 \\
Predicting & 0.87 \\
Measuring & 0.32 \\
Total Score & 0.93 \\
\hline
\end{tabular}

Educational Scaffolding Strategies Guide

The researchers prepared a set of activities designed in a way that develops educational scaffolding strategies in order to implement them on children. This preparation includes the general goals of each activity taking into consideration the steps to implement the activity and its principles through preparing the necessary means, tools and strategies, activities and games to be implemented, and the time needed to achieve them, and determine which strategies of educational scaffolding to be developed in these activities.

The foundation that educational scaffolding strategies was based on

- The suitability of activities for children reconstructions and their mental development level.

- The extent to which they achieved the goals.

- The extent to which they took into consideration children needs and tendencies.

- The simplicity and easiness of the language.

- The clarity of instructions

To verify the sincerity of the content of educational scaffolding strategies, the guide was presented in its preliminary form to a number of (12) arbitrators, specialized in education and psychology, to evaluate it with regard to clarity of its steps according to educational scaffolding strategies, and the extent of their suitability for kindergarten children from 5-6 years of age on one hand, and on the other, the appropriateness of educational scaffolding strategies in developing basic scientific operations, and their safety in terms of language formulation.

\section{Procedures of the Study}

- Access to previous educational studies (university theses, and educational researches that tackled the effectiveness of educational scaffolding strategies in developing basic scientific operations).

- Access to educational literature through an in-depth study of the two study variables: educational scaffolding strategies, and basic scientific operations.

- The researchers prepared a list of basic scientific operations blinds to the subjects taught to the experimental group, in line with educational scaffolding strategies.

- The researchers prepared teachers guide on the subjects taught to the experimental group, in line with educational scaffolding strategies.

- Applying the test on exploratory sample consisting of (15) children in Topaz Academy, subordinate to the private sector of The Ministry of Education/Amman, to check validity of the test.

- Selecting the basic sample using the random sample method. The sample consisted of (45) children, selected from IEC kindergarten Amman. The sample was divided into experimental and control.

- Applying educational scaffolding strategies by the researcher to the children of the experimental group. This was conducted the first semester 2019/2020 as of 1/10/2019 till 3/11/2019, one class per day.

- Applying the Pre-Test to the two study groups that were chosen in a simple random way, then conducting the Pre-Test on 29/9/2019 to verify the equivalence of the two study groups.

- Applying Post-Test for the two groups of the study on 4/11/2019, after the application was over.

- Applying Consecutive-Test for the experimental and control groups on 4/12/2019.

- Discussing the results and in light of that the researcher came up with several recommendations.

\section{Result of the Analysis}

The purpose of this study to investigate the effectiveness of educational scaffolding strategies in developing basic scientific operations of kindergarten children in Jordan, the results of the study are presented as follows:

Results of Question One: Are there statistically differences at the significant level $(\alpha \leq 0.05)$ between the mean scores of the experimental group (educational scaffolding strategies) in the Post-Test at the basic scientific operations scale (observing, classifying, predicting, and measuring skills) and those of their counter parts in the control group (traditional) of kindergarten children?

To answer this question of the study concerning whether there are any significant differences in children mean scores of the experimental group and the control group on the overall score of the Post-Test of the basic scientific operations due to the teaching methods (scaffolding vs traditional), means and standard deviations of 
the overall Pre-Test and Post-Test children scores; in addition to their adjusted means and standard errors were calculated as presented in Table (5).

Table (5) results of the Overall Pre \& Post-test Children Scores

\begin{tabular}{|c|c|c|c|c|c|c|c|}
\hline \multirow{2}{*}{ Group } & \multirow{2}{*}{$\mathbf{N}$} & \multicolumn{2}{|c|}{ Pre-test } & \multicolumn{2}{|c|}{ Post-test } & \multirow{2}{*}{ Adjusted mean } & \multirow{2}{*}{ standard errors } \\
\hline & & Mean & Sd & Mean & Sd & & \\
\hline Experimental & 23 & 8.18 & 2.92 & 27.18 & 1.29 & 27.03 & 0.440 \\
\hline Control & 22 & 7.57 & 3.87 & 12.78 & 3.46 & 12.93 & 0.430 \\
\hline
\end{tabular}

Table (5) shows the mean scores, standard deviations and the adjusted means of the overall performance of the educational scaffolding strategies group and the control group on the Pre-test and the Post-test. Moreover, Table (5) shows a difference in the adjusted mean scores of the educational scaffolding strategies group and the control group in favor of the educational scaffolding strategies group.

For better examination and clearer interpretation, ANCOVA was used to analyze children scores based on the variable of the teaching method, as shown in Table (6):

Table (6) The Results of ANCOVA of the Children Scores on the Post-Test

\begin{tabular}{ccccccc}
\hline Source & Sum of Squares & df & Mean Square & f & Sig & Partial Eta Squared \\
\hline Pre-test & 120.95 & 1 & 120.95 & 28.50 & 0.00 & \\
Teaching Method & 2216.45 & 1 & 2216.45 & 522.28 & $0.00^{*}$ & 0.93 \\
Error & 178.24 & 42 & 4.24 & & & \\
Corrected Total & 2630.58 & 44 & & & & \\
\hline
\end{tabular}

Table (6) shows that there is a significant difference at $(\alpha=0.05)$ between the adjusted mean scores of the overall performance on the Post-Test in favor of the experimental group, learned with educational scaffolding strategies compared with the control group who learned with traditional method.

The adjusted mean of the experimental group was found to be (27.03) in comparison with the mean score of the control group (12.39), who were taught in the traditional method. Furthermore, Table (6) shows the effect size of educational scaffolding strategies on the Post-Test. This was calculated through applying the Eta square statistics to the test results. The table shows Eta square value was (0.93). This percentage suggests that the effect size of educational scaffolding strategies on the Post-Test was big.

In addition, means and standard deviations for each basic scientific operation, Pre and Post-Test scores, and adjusted means and standard deviations for each level in the Post-Test scores, were calculated and tabulated in Table (7):

Table (7) results for Each Level in the Pre and Post-test Scores

\begin{tabular}{cccccccc}
\hline \multirow{2}{*}{ Basic scientific operations } & \multirow{2}{*}{ Group } & \multicolumn{2}{c}{ Total pre-test } & \multicolumn{2}{c}{ Total post-test } & \multicolumn{3}{c}{ Adjustment } \\
& & Mean & Sd & Mean & Sd & Mean & Sd \\
\hline \multirow{2}{*}{ Observing } & Experimental & 2.23 & 1.60 & 7.77 & 0.53 & 7.73 & 0.16 \\
& Control & 1.91 & 1.59 & 3.61 & 1.08 & 3.65 & 0.16 \\
\multirow{2}{*}{ Classifying } & Experimental & 2.09 & 1.11 & 5.77 & 0.53 & 5.73 & 0.21 \\
& Control & 1.96 & 1.30 & 2.87 & 1.42 & 2.91 & 0.20 \\
\multirow{2}{*}{ Predicting } & Experimental & 2.14 & 1.42 & 7.64 & 0.73 & 7.61 & 0.24 \\
& Control & 2.09 & 1.44 & 3.39 & 1.64 & 3.42 & 0.23 \\
Measuring & Experimental & 1.73 & 1.28 & 6.00 & 0.00 & 5.97 & 0.22 \\
& Control & 1.61 & 1.31 & 2.91 & 1.44 & 2.94 & 0.21 \\
\hline
\end{tabular}

Table (7) shows that there are differences in the mean scores for each level of the Post-Test attributed to the difference in the treatment variable, in favor of the experimental group who were taught through educational scaffolding strategies.

In order to test the significance of these differences, Multivariate analysis of covariance (MANCOVA) was applied on each of the Post-Test levels as presented in Table (8): 
Table (8) MANCOVA Results for Each of the Post-Test Levels

\begin{tabular}{|c|c|c|c|c|c|c|c|}
\hline Source & $\begin{array}{c}\text { Dependent } \\
\text { Variable }\end{array}$ & $\begin{array}{c}\text { Type III Sum of } \\
\text { Squares }\end{array}$ & df & $\begin{array}{c}\text { Mean } \\
\text { Square }\end{array}$ & $\mathbf{f}$ & Sig. & $\begin{array}{l}\text { Partial Eta } \\
\text { Squared }\end{array}$ \\
\hline \multirow{4}{*}{$\begin{array}{l}\text { Observing } \\
\text { (pre-test) }\end{array}$} & Observing & 4.069 & 1 & 4.069 & 6.916 & 0.012 & \\
\hline & Classifying & 1.208 & 1 & 1.208 & 1.261 & 0.268 & \\
\hline & Predicting & 0.275 & 1 & 0.275 & 0.218 & 0.644 & \\
\hline & Measuring & 2.535 & 1 & 2.535 & 2.469 & 0.124 & \\
\hline \multirow{4}{*}{$\begin{array}{l}\text { Classifying } \\
\text { (pre-test) }\end{array}$} & Observing & 0.528 & 1 & 0.528 & 0.897 & 0.349 & \\
\hline & Classifying & 2.961 & 1 & 2.961 & 3.092 & 0.087 & \\
\hline & Predicting & 8.278 & 1 & 8.278 & 6.559 & 0.014 & \\
\hline & Measuring & 0.248 & 1 & 0.248 & 0.242 & 0.626 & \\
\hline \multirow{4}{*}{$\begin{array}{l}\text { Predicting } \\
\text { (pre-test) }\end{array}$} & Observing & 1.039 & 1 & 1.039 & 1.766 & 0.192 & \\
\hline & Classifying & 1.329 & 1 & 1.329 & 1.387 & 0.246 & \\
\hline & Predicting & 3.274 & 1 & 3.274 & 2.594 & 0.115 & \\
\hline & Measuring & 0.382 & 1 & 0.382 & 0.373 & 0.545 & \\
\hline \multirow{4}{*}{$\begin{array}{l}\text { Measuring } \\
\text { (pre-test) }\end{array}$} & Observing & 0.311 & 1 & 0.311 & 0.528 & 0.472 & \\
\hline & Classifying & 0.812 & 1 & 0.812 & 0.848 & 0.363 & \\
\hline & Predicting & 0.005 & 1 & 0.005 & 0.004 & 0.953 & \\
\hline & Measuring & 1.314 & 1 & 1.314 & 1.28 & 0.265 & \\
\hline \multirow{4}{*}{ Group } & Observing & 185.634 & 1 & 185.634 & 315.499 & $0.00^{*}$ & 0.89 \\
\hline & Classifying & 87.91 & 1 & 87.91 & 91.799 & $0.00 *$ & 0.702 \\
\hline & Predicting & 195.454 & 1 & 195.454 & 154.871 & $0.00 *$ & 0.799 \\
\hline & Measuring & 101.618 & 1 & 101.618 & 98.971 & $0.00 *$ & 0.717 \\
\hline \multirow{4}{*}{ Error } & Observing & 22.947 & 39 & 0.588 & & & \\
\hline & Classifying & 37.348 & 39 & 0.958 & & & \\
\hline & Predicting & 49.22 & 39 & 1.262 & & & \\
\hline & Measuring & 40.043 & 39 & 1.027 & & & \\
\hline \multirow{4}{*}{ Total } & Observing & 226.311 & 44 & & & & \\
\hline & Classifying & 145.244 & 44 & & & & \\
\hline & Predicting & 273.2 & 44 & & & & \\
\hline & Measuring & 152.978 & 44 & & & & \\
\hline
\end{tabular}

Table (8) demonstrates that there are statistically significant differences at the statistically significant level $(\alpha=0.05)$ between the two adjusted mean scores of each level in the Post-Test, attributed to the treatment variable, in favor of the experimental group who were taught through educational scaffolding strategies. In addition, Table (8) also shows that the effect size of the basic scientific operations ranged between $(0.702$ $0.890)$, Observing ranked in the highest position with an effect size of (0.890). Whereas, Classifying ranked in the lowest position with an effect size of (0.702).

Results of Question Two: Are there statistically differences at the significant level $(\alpha \leq 0.05)$ between the mean scores of the experimental group (educational scaffolding strategies) in the Post-test of kindergarten children due to the gender?

To investigate the second question, means and standard deviation of males and females at the experimental group results were computed. (Independent samples t-test) was used to measure the significance of differences described in Table (9):

Table (9) results of the Impact of Gender on the Performance of Children in the Experimental Group

\begin{tabular}{|c|c|c|c|c|c|c|c|}
\hline $\begin{array}{c}\text { Basic scientific } \\
\text { operations }\end{array}$ & Gender & No. & Mean & Sd & df & $\mathbf{t}$ & Sig. \\
\hline \multirow{2}{*}{ Observing } & Male & 13 & 7.85 & 0.38 & \multirow{2}{*}{20} & \multirow{2}{*}{0.776} & \multirow{2}{*}{0.447} \\
\hline & Female & 9 & 7.67 & 0.71 & & & \\
\hline \multirow{2}{*}{ Classifying } & Male & 13 & 5.85 & 0.38 & \multirow{2}{*}{20} & \multirow{2}{*}{0.776} & \multirow{2}{*}{0.447} \\
\hline & Female & 9 & 5.67 & 0.71 & & & \\
\hline \multirow{2}{*}{ Predicting } & Male & 13 & 7.62 & 0.77 & \multirow{2}{*}{20} & \multirow{2}{*}{-0.159} & \multirow{2}{*}{0.875} \\
\hline & Female & 9 & 7.67 & 0.71 & & & \\
\hline \multirow{2}{*}{ Measuring } & Male & 13 & 6.00 & 0.00 & \multirow{2}{*}{20} & \multirow[b]{2}{*}{-} & \multirow[b]{2}{*}{ - } \\
\hline & Female & 9 & 6.00 & 0.00 & & & \\
\hline \multirow{2}{*}{ Total } & Male & 13 & 27.31 & 1.32 & \multirow{2}{*}{20} & \multirow{2}{*}{0.538} & \multirow{2}{*}{0.596} \\
\hline & Female & 9 & 27.00 & 1.32 & & & \\
\hline
\end{tabular}

Table (9) shows that there are no statistically significant differences at the level of significance $(\alpha=0.05)$ between males and females at the experimental group, in addition to all operations or skills. 
Results of Question Three: Are there statistically differences at the significant level $(\alpha \leq 0.05)$ between the mean scores of the experimental group (educational scaffolding strategies) in the Post-Test and Consecutive-test?

To answer this question, a paired samples T-Test was used to detect the significance of the differences between the two dimensions of the Post and Consecutive measurement on the scale of basic scientific operation skills for the responses of the members of the experimental group, as shown in Table (10):

Table (10) Paired Samples t-test

\begin{tabular}{|c|c|c|c|c|c|c|c|}
\hline Basic Scientific Operations & Test & No. & Mean & Sd & df & $\mathbf{t}$ & Sig. \\
\hline \multirow{2}{*}{ Observing } & Post & 22 & 7.77 & 0.53 & \multirow{2}{*}{21} & \multirow{2}{*}{4.46} & \multirow{2}{*}{$0.00 *$} \\
\hline & Consecutive & 22 & 7.00 & 0.82 & & & \\
\hline \multirow{2}{*}{ Classifying } & Post & 22 & 5.77 & 0.53 & \multirow{2}{*}{21} & \multirow{2}{*}{2.73} & \multirow{2}{*}{$0.01 *$} \\
\hline & Consecutive & 22 & 5.09 & 0.87 & & & \\
\hline \multirow{2}{*}{ Predicting } & Post & 22 & 7.64 & 0.73 & \multirow{2}{*}{21} & \multirow{2}{*}{3.60} & \multirow{2}{*}{$0.00^{*}$} \\
\hline & Consecutive & 22 & 6.77 & 0.92 & & & \\
\hline \multirow{2}{*}{ Measuring } & Post & 22 & 6.00 & 0.00 & \multirow{2}{*}{21} & \multirow{2}{*}{1.70} & \multirow{2}{*}{0.10} \\
\hline & Consecutive & 22 & 5.82 & 0.50 & & & \\
\hline \multirow{2}{*}{ Total } & Post & 22 & 27.18 & 1.30 & \multirow{2}{*}{21} & \multirow{2}{*}{6.18} & \multirow{2}{*}{$0.00 *$} \\
\hline & Consecutive & 22 & 24.68 & 1.29 & & & \\
\hline
\end{tabular}

It is clear from the data presented in Table (10) that there are statistically significant differences at the level of significance $(\alpha=0.05)$ between the mean of scores of the members of the experimental group on the scale of the basic scientific operations between the Post-Test and Consecutive-Test in favor of Post-Test, in addition to the fields (Observing, Classifying, and Predicting Skills). Furthermore, Table (10) shows that there are no statistically significant differences at the level of significance $(\alpha=0.05)$ between the mean score's members of the experimental group on the Measuring Skills.

Results of Question Four: Are there statistically differences at the significant level $(\alpha \leq 0.05)$ between the mean scores of the experimental group (educational scaffolding strategies) in the Consecutive-test of kindergarten children due to the gender?

To investigate the fourth question, means and standard deviation of males and females at the experimental group results were computed. (Independent samples T-Test) was used to measure the significance of differences described in Table (11):

Table (11) Results of the Impact of Gender on the Performance of Children in the Experimental Group in the Consecutive-test

\begin{tabular}{cccccccc}
\hline Basic Scientific Operations & Gender & No. & Mean & Sd & df & t & Sig. \\
\hline \multirow{2}{*}{ Observing } & Male & 13 & 7.15 & 0.80 & 20 & 1.07 & 0.299 \\
& Female & 9 & 6.78 & 0.83 & & & \\
Classifying & Male & 13 & 5.00 & 0.91 & 20 & -0.581 & 0.568 \\
& Female & 9 & 5.22 & 0.83 & & & \\
Predicting & Male & 13 & 6.77 & 0.83 & 20 & -0.021 & 0.984 \\
& Female & 9 & 6.78 & 1.09 & & & \multirow{2}{*}{0.594} \\
Measuring & Male & 13 & 5.77 & 0.60 & 20 & -0.541 & 0.594 \\
& Female & 9 & 5.89 & 0.33 & & & \\
Total & Male & 13 & 24.69 & 1.03 & 20 & 0.045 & 0.965 \\
& Female & 9 & 24.67 & 1.66 & &
\end{tabular}

Table (11) shows that there are no statistically significant differences at the level of significance $(\alpha=0.05)$ between males and females at the experimental group in the Consecutive-test, in addition to all operations.

\section{Discussion}

The results of the study supported the initial predictions that educational scaffolding strategies has a positive effect on kindergarten children's basic scientific operation skills. Children of the experimental group who was taught through educational scaffolding strategies gained higher mean scores in the four basic scientific operation skills of the basic scientific operation post-test. The significant differences in the mean scores of both groups on the post-test showed that the experimental group children were positively affected by the educational scaffolding strategies. Comparing the means of the experimental group (27.03) to the means of the control group (12.39) in the post-test, reflected the positive improvement in favor of the experimental group.

At the same time, the results of Eta square were (0.93) this suggests the effect size of educational scaffolding strategies on the post-test was big. On the other hand, basic scientific operations skills (observing, predicting, classifying, and measuring) ranged between (0.702-0.890), observing skills ranked in the highest position, whereas classifying skills ranked the lowest skill; such skills was also mentioned in previous studies such as: Maranan (2017), El-Keey (2017). This indicates that there was a considerable effect of educational scaffolding strategies on basic scientific operation skills. These findings are in line with the previous studies 
which proved that educational scaffolding strategies help in improving kindergarten children's basic scientific operation skills or any other skills such as: Ejekwu, \& Inyon (2019), Pentimonti, Justice, Yeomans-Maldonado, McGinty, Slocum, \& O’Connell (2017), Al-Aila (2015), Hsin, \& Kai Wu (2011), Sun (2011), Pentimonti (2011), Pentimonti, \& Justice (2010).

The findings of the study showed that using ESS had a significant effectiveness on kindergarten children basic scientific operation skills in the experimental group, who were taught according to ESS, compared with the control group which were taught according to the ordinary method. This means that the group that studied by using ESS surpassed the group that followed the ordinary method. ESS is considered effective in improving kindergarten children achievement and upgrading them.

\section{Limitations and future Recommendations}

The current study deals with the effectiveness of educational scaffolding strategies in developing basic scientific operations, the sample was kindergarten children of second level (kg2) males and females 5-6 years old in Amman/Jordan, the study was conducted in the kindergarten of the Islamic Educational College (IEC) affiliated with the Ministry of Education in Amman/Jordan, and it was conducted during the period extending from (1/10/2019 to 3/11/2019), the first semester (2019-2020). Generalization of the results of the current study is determined by the truth and reliability of study tools. In the light of study results, the following recommendations are offered:

- Curriculum designers and developers, should utilize a significant amount of ESS in textbooks, and curricula should be designed to emphasize ESS., they should enrich the curriculum based on ESS techniques, curriculum should be suited to children interests, needs and abilities.

- Supervisors and specialists should conduct training workshops that aim to promote teachers' abilities in teaching through implementing ESS.

- Familiarizing teachers with different skills based on appropriate ESS techniques, distribute instructional materials that increase teachers' awareness of the necessity of using ESS in their classes.

- Teachers should adopt the ESS in teaching BSOS, and shift from the ordinary teaching methods to ESS.

- Briefly, the researcher recommends that teachers, designers and supervisors take scaffolding more into account.

\section{Conclusion}

Based on the findings of this study, the following conclusions were reached:

- Educational scaffolding is an effective strategy for improving kindergarten children basic scientific operations, it assists children who need scaffold to reach their peers level of knowledge.

- Scaffolding is just one of the many techniques available to invest in education but it has a significant role in supporting learners to progress within the ZPD. The main aspiration of scaffolding within the ZPD is to conceive children being actively engaged in their learning with the future prospect of becoming self-directed, lifelong learners.

- Educational scaffolding strategy proves to be a key feature of effective teaching especially teaching basic scientific operations. Thus, teachers are invited to reconsider the ordinary methods and adopt new ones that depend on support and assistance.

- Providing assistance and support to children through educational scaffolding strategies optimize children learning and enhance basic scientific operation skills.

- Educational scaffolding strategies can bridge a gap between what children know and can do, versus what they don't know or can't do, but intended to know and do. It is one of the principles of effective strategies that enables teachers to accommodate individual children needs.

- Educational scaffolding strategies provides various techniques of support such as: show and tell; models; cues; tap into prior knowledge; prompts; hints; partial solutions; think-aloud modeling; give time to talk; pre-teach vocabulary; use visual aids; pause, ask question, pause, review; and direct instruction. The differences in the types and amounts of scaffolds provided changes depending on the age of the children receiving the support, and the task itself.

- Educational scaffolding strategies develops the cooperative learning within the group members, group work techniques help children to exchange their ideas and help each other.

- Educational scaffolding strategies stimulate children towards an independent practice of basic scientific operation skills, once the children do the tasks independently, scaffolding is removed.

- The current study came to the conclusion that educational scaffolding strategies gave children a chance to be involved, motivated and confident. Also proved that scaffolding can be flexibly designed to meet the needs of diverse children who all have different zones of proximal development. 


\section{References}

Abu-Fool, N. (2016). The Efficiency of the Integrated Experience Curriculum in Developing Basic Science Operations in Kindergarten Children of Jordan. Isra University: Amman, Jordan (13-15).

Al-Aila, M. (2015). Effectiveness of Using Scaffolding Strategy on Developing Seventh Graders' Reading Comprehension Skills. Unpublished Master Thesis, The Islamic University of Gaza, Palestine (3).

Berk, L., \& Winsler, A. (1995). Scaffolding children's learning: Vygotsky and early childhood education. Washington, DC: National Association for the Education of Young Children.

Bodrova, E., \& Leong, D. (2007). Tools of the mind: The Vygotskian approach to early childhood education. Upper Saddle River, NJ: Prentice Hall (122-123).

Bredekamp, S. (1987). Developmentally Appropriate Practice in Early Childhood Programs Serving Children from Birth through Age 8. Washington, DC: NAEYC.

Bruner, J. (1981). The social context of language acquisition. Language \& Communication, 1, 155 - 178.

Cobb, P. (1996). Where is the mind? A coordination of sociocultural and cognitive constructivist perspectives. In: Fosnot CT (ed.) Constructivism: Theory, Perspectives, and Practice. New York: Teacher's College Press, 34-52.

Coltman, P., Petyaeva, D., \& Anghileri, J. (2002). Scaffolding learning through meaningful tasks and adult interaction. Early Years: Journal of International Research and Development, 22, 39-49.

Ejekwu, P., \& Inyon, A. (2019). Effect of Scaffolding Instructional Strategies and Gender on Performance of Pupils in Basic Science and Technology in Rivers State, Nigeria. Journal of Global Research in Education and Social Science, 13(5), 164-171.

El-Keey, S. (2017). Developing Science Process Skills and Some of Accompanying Skills Through Observation of Life Cycle of Silkworm by Kindergarten Child. The Online Journal of New Horizon in Education, 7(1), 53-63.

Franzoi, S. (2014). Essentials of Psychology, (3rd ed.). USA: Cengage Learning.

Harkness, S., \& Super, C. (2002). Culture and parenting. In: Bornstein M (ed.) Handbook of Parenting: Biology and Ecology of Parenting, 2(2), 253-280. Mahwah, NJ: Lawrence Erlbaum Associates, Inc.

Hsin, C., \& Kai Wu, H. (2011). Using Scaffolding Strategies to Promote Young Children's Scientific Understandings of Floating and Sinking. Published Research Online, Journal of Science Education and Technology, 20(5), 656-666.

Juel, C. (1996). What makes literacy tutoring effective. Reading Research Quarterly, 31(3), 268-289.

Khataibeh, M. (2011). Science Education for All, (3rd ed.). Amman: Dar Almaserah (122).

Maranan, V. (2017). Basic Process Skills and Attitude Toward Science: Inputs to an Enhanced Students' Cognitive Performance. Unpublished Master Thesis, Laguna State Polytechnic University, San Pablo.

Pentimonti, J., \& Justice, L. (2010). Teachers' Use of Scaffolding Strategies During Read Alouds in the Preschool Classroom. Published research online, Early Childhood Educ J, 37, 241-248.

Pentimonti, J. (2011). Meeting the Needs of All Children: The Use and Impact of Scaffolding in the Preschool Classroom. The Ohio State University, USA, Ohio.

Pentimonti, J., Justice, L., Yeomans-Maldonado, G., McGinty, A., Slocum, L., \& O’Connell, A. (2017). Teachers' Use of High and Low-Support Scaffolding Strategies to Differentiate Language Instruction in High-Risk/Economically Disadvantaged Settings. Published Research Online, Journal of Early Intervention, $39(2), 125-146$

Rogoff, B. (1990). Apprenticeship in thinking: Cognitive development in social context. New York: Oxford.

Shehata, H., \& Najjar, Z. (2003). Dictionary of Educational and Psychological Terms, (1st ed.). Cairo: Al-Daar Almaserah Allubnaniah (155-230).

Sun, J. (2011). Scaffolding Preschool Children's Problem Solving: A Comparison Between Chinese Mothers and Teachers Across Multiple Tasks. Journal of Early Childhood Research, 10(3), 246-266.

Vygotsky, L. (1978). Mind in society: The development of higher psychological processes. Cambridge, MA, Harvard University Press.

Wertsch, J. (1984). The zone of proximal development: Some conceptual issues. New Directions for Child and Adolescent Development, 23, 7-18.

Zaytoon, A. (2008). The Extent of the Acquisition of Science Operations Among Students in The Elementary Stage in Jordan and Its Relation to The Variables of the Academic Grade and Educational Achievement. Educational Science Studies, 35(2), 327-392.

Zaytoon, K. (2009). Science and Scientific Processes-Scientific Framework for Evaluating Science Under the Spot of International Studies-For Science and Mathematics, (1st ed.). Cairo: Books World (123). 